\title{
Density-habitat relationships of white-tailed deer (Odocoileus virginianus) in Finland
}

\author{
Jenni Poutanen ${ }^{1}$, Angela Fuller ${ }^{2}$, Jyrki Pusenius ${ }^{3}$, J Royle ${ }^{4}$, Mikael Wikström $^{5}$, and Jon \\ Brommer $^{1}$ \\ ${ }^{1}$ University of Turku \\ ${ }^{2}$ U.S. Geological Survey \\ ${ }^{3}$ Natural Resources Institute Finland \\ ${ }^{4}$ USGS \\ ${ }^{5}$ Finnish Wildlife Agency
}

January 24, 2022

\begin{abstract}
In heterogeneous landscapes, habitat preference constitutes a crucial link between landscape and population-level processes such as density and sex ratios. We conducted a non-invasive genetic study of white-tailed deer in southern Finland using fecal samples. We estimated deer density as a function of landcover type using a Spatial Capture-Recapture (SCR) model. Second-order habitat selection of white-tailed deer revealed particularly high densities in fields and mixed forest, and thirdorder selection was related to distance to fields and transitional woodlands (clearcuts). Including landscape heterogeneity improved model fit compared with assuming a homogenous landscape. Our findings underline the importance of including habitat covariates when estimating density.
\end{abstract}

\section{Density-habitat relationships of white-tailed deer(Odocoileus virginianus) in Finland}

Poutanen Jenni ${ }^{1}$, Fuller Angela K. ${ }^{2}$, Pusenius $\mathrm{Jyrki}^{3}$, Royle J. Andrew ${ }^{4}$, Wikström Mikael ${ }^{5}$, Brommer Jon $\mathrm{E}^{6}$.

\section{AFFILIATIONS}

1) jenni.poutanen@utu.fi ; Corresponding author

ORCID: 0000-0003-0687-1627

Department of Biology, University Hill, 20014 University of Turku, Finland

and Natural Resources Institute Finland, Itäinen Pitkäkatu 4 A, 20520 Turku, Finland

2) angela.fuller@cornell.edu

ORCID: 0000-0002-9247-7468

U.S. Geological Survey, New York Cooperative Fish and Wildlife Research Unit, Department of Natural Resources and the Environment, Cornell University, Ithaca, NY 14853

3) jyrki.pusenius@luke.fi

ORCID: 0000-0003-0450-7530

Natural Resources Institute Finland, Yliopistokatu 6, 80100 Joensuu, Finland 
4) aroyle@usgs.gov

ORCID: 0000-0003-3135-2167

U.S. Geological Survey, Eastern Ecological Science Center, Laurel MD 20708

5) mikael.wikstrom@riista.fi

ORCID: 0000-0002-5029-2094

Finnish Wildlife Agency, Sompiontie 1, 00730 Helsinki, Finland

6) jon.brommer@utu.fi

ORCID: 0000-0002-2435-2612

Department of Biology, University Hill, 20014 University of Turku, Finland

and NOVIA University of Applied Sciences, Campus Raseborg, 10600 Ekenäs, Finland

\begin{abstract}
In heterogeneous landscapes, habitat preference constitutes a crucial link between landscape and populationlevel processes such as density and sex ratios. We conducted a non-invasive genetic study of white-tailed deer in southern Finland using fecal samples. We estimated deer density as a function of landcover type using a Spatial Capture-Recapture (SCR) model. Second-order habitat selection of white-tailed deer revealed particularly high densities in fields and mixed forest, and third-order selection was related to distance to fields and transitional woodlands (clearcuts). Including landscape heterogeneity improved model fit compared with assuming a homogenous landscape. Our findings underline the importance of including habitat covariates when estimating density.
\end{abstract}

Keywords: non-invasive genetics, Odocoileus virginianus, population density, spatial capture-recapture, wildlife ecology, white-tailed deer

This draft manuscript is distributed solely for purposes of scientific peer review. Its content is deliberative and predecisional, so it must not be disclosed or released by reviewers. Because the manuscript has not yet been approved for publication by the U.S. Geological Survey (USGS), it does not represent any official USGS finding or policy.

\title{
Introduction
}

Wildlife management requires knowledge of population parameters such as density, sex ratio, and productivity. Population densities are often dependent on the quality of occupied habitat as animals rarely use all available habitats equally (Fretwell 1969, Maier et al. 2005, Bjørneraas et al. 2012). Thus, habitat selection of animals is an important part of management and conservation of many species (Allen and Singh 2016). When landscapes are heterogeneous and animals preferentially use certain habitats, the study of habitat selection is necessary in order to understand how habitat is linked to population abundance (Royle et al. 2018). In particular, by assuming a homogeneous landscape or ignoring the effect of landscape heterogeneity on populations, estimates of density can be biased (Royle et al. 2013a).

The preference of animals for certain habitats, i.e. the habitat (or resource) selection can be viewed as a process with three orders (Johnson 1980). The first order is the spatial distribution of the species, the topic often studied in landscape ecology. Second and the third order habitat selection is more of interest in population ecology. Second order habitat selection describes how individuals are distributed within the species' range in relation to environmental features. Third order selection describes within home range selection of habitats by individuals.

Commonly, habitat selection has been studied invasively using telemetry e.g. by attaching GPS or VHF collars on animals (Morris et al. 2016, Bose et al. 2018). Live capturing a large number of individuals, especially of large species, can be not only harmful for animals but also expensive and impractical. Therefore, even 
though information on space usage by telemetry can be detailed, it often represents only a few individuals that may not be representative of the population. Telemetry data thus represents individual-level rather than population-level habitat selection. The use of non-invasive genetic methods provides the possibility to study animal space use without physically marking and recapturing them, for instance by collecting feces (Granroth-Wilding et al. 2017, Hagemann et al. 2018) or hair (Sun et al. 2017, O'Meara et al. 2018) left in specific trap or collection devices in the environment (Waits and Paetkau 2005). Spatial information of the individuals is recorded from the capture locations and individual identification is obtained by extracting DNA from the sample and genotyping the samples. Even though sampling in the field and analyzing noninvasive DNA in the laboratory can be laborious and expensive, the resulting genotype data can provide valuable population-level information of space use.

Spatially explicit records of individuals can be analyzed using spatial capture-recapture (SCR), a spatial extension of long-established capture-recapture methods (Efford 2004, Royle et al. 2014). Apart from inferring density, SCR can also be simultaneously used to examine spatial processes of the populations e.g. habitat selection (Royle et al. 2013a) and landscape connectivity (Royle et al. 2013b, Sutherland et al. 2015, Fuller et al. 2016). SCR connects population-level information to the spatial structure of the landscape by accounting for spatial location of the sampling sites and for spatial distribution of the individual encounters. Because SCR includes space explicitly, it allows inclusion of habitat covariates into the models of both density and detection probability. The relationship between the habitat and the density distribution of populations, i.e. second order habitat selection, is modeled by SCR as a density of activity centers as a function of habitat covariates. To study the habitat use of individuals within their home ranges, i.e. third order habitat selection, the habitat structure around the sampling locations or traps can be incorporated to SCR analyses to model how those covariates affect encounter probabilities (Royle et al. 2018). SCR can estimate the effect of certain habitat types on density and encounter probability, even if individuals are not directly encountered in that habitat, by predicting the locations of individual home range centers in the vicinity of the sample units. One main application of SCR has been research on large carnivores (Proffitt et al. 2015, Sun et al. 2017, Stetz et al. 2019, Welfelt et al. 2019), but non-invasive DNA sampling with SCR has also been used to study the relationship of mule deer (Odocoileus hemionus) population density and habitat structure (Brazeal et al. 2017).

White-tailed deer (Odocoileus virginianus) inhabit a large variety of terrestrial habitats and feed on various vegetation types (Halls 1984). In Finland, it has become one of the most important game species after its remarkable and continuing growth in abundance since 1934, when the species was introduced from North America. It is listed as a potentially or locally harmful species in Finland's National Strategy on Invasive Alien Species (2012). One of the biggest impacts of white-tailed deer are deer-vehicle collisions, but in the areas of the densest population the species can also cause damage to agriculture and forestry for instance by eating vegetable crops and tree seedlings. For the management of this species, it is important not only to estimate abundance, but also to understand what habitat types the white-tailed deer prefers in Finland and how that affects the species densities. To this end, we conducted a SCR based study using fecal DNA in southwestern Finland. Our aim was to understand how white-tailed deer use available habitat types in a short time period (about two to three weeks) just prior to the start of the hunting season. The study was repeated in the same study area in two consecutive years. Additionally, we evaluated the importance of habitat covariates when inferring this species' density by comparing the "standard" SCR model where density is assumed to be homogeneously distributed over space to inhomogeneous SCR models considering a heterogeneous landscape.

\section{Materials and methods}

\section{Sampling}

We sampled fecal pellets of white-tailed deer in 2016 and 2017. The study area in southwestern Finland (central coordinate: $60^{\circ} 51^{\prime} 56^{\prime \prime} \mathrm{N}, 22^{\circ} 49^{\prime} 26^{\prime \prime} \mathrm{E}$ (WGS84)) is forest, surrounded by agricultural fields, which is a typical landscape for the region. Sampling followed the protocol of Poutanen et al. (2019) but with small changes to the sampling design. We used a cluster design with 23 clusters with four sampling plots in each 
for a total of 92 plots. We modified the sampling of Poutanen et al. (2019) so that the distances between the clusters were decreased from $500 \mathrm{~m}$ to $300 \mathrm{~m}$ and distance between the plots was reduced from $100 \mathrm{~m}$ to $60 \mathrm{~m}$ in order to obtain more spatial recaptures. In order to sample a closed population, sampling was conducted in the autumn before the white-tailed deer hunting season, when migration is also limited and fawns of the year remain with their mothers. In 2016, we sampled in September, but in 2017 sampling was initiated in August, due to the earlier timing of the hunting season. In 2016, we visited sampling plots weekly for three visits and in 2017 every four days for a total of six visits. During the first visit, the plots were cleared of feces, which were then discarded and not used in the subsequent analysis. Therefore, there were two sampling occasions in 2016 and five in 2017. In 2017, plots were visited more frequently than in 2016 because the results of the earlier study of the authors suggested that decreasing the sampling interval would allow collection of scats more frequently, reducing environmental exposure and DNA degradation, thus improving genotyping success rates (Poutanen et al. 2019).

\section{Genetic analysis}

DNA extraction and individual identification followed the protocol of Poutanen et al. (2019). The only modifications for the microsatellite PCR protocol were that final concentration of primer Rt5 was decreased from $0.2 \mu \mathrm{mol} / \mathrm{l}$ to $0.1 \mu \mathrm{mol} / \mathrm{l}$ and BSA concentration from $0.1 \mu \mathrm{g} / \mu \mathrm{l}$ to $0.01 \mu \mathrm{g} / \mu \mathrm{l}$. We genotyped samples using 14 microsatellite markers and used the multitube approach by performing three PCR replicates for each sample to minimize genotyping errors (Taberlet et al. 1996). Samples which were successfully amplified with at least 11 loci were used to establish individual identity. Consensus genotypes were constructed with a rule that alleles of homozygous loci were needed to amplify three times and of heterozygous loci two times in order to be accepted as final genotype (Jansson et al. 2014, Stansbury et al. 2014). When matching genotypes, we allowed two mismatches in different loci between the samples in order to accept them as representing the same individual. Thus, we required at least six matching loci between the samples to assign them to the same individual. This was a sufficient number of loci for identification as when counting the probability of identity (PI) values based on the six most uninformative loci the PI values were in the range of recommendations ( $\mathrm{PI}=0.0003$ in 2016 and $\mathrm{PI}=0.0001$ in $2017, \mathrm{PID}_{\mathrm{sib}}=0.02$ in both years) (Waits et al. 2001). Consensus genotypes were matched to individuals using the software Cervus v. 3.0.7 (Kalinowski et al. 2007) and Gimlet v. 1.3.3 (Valière 2002). At least one DNA sample of each identified individual were sexed with X- and Y- chromosome specific primer pair ZFX/ZFY following the protocol of Poutanen et al. 2019.

We used the consensus genotype data to calculate deviations from Hardy Weinberg Equilibrium using Genepop v. 4.2 (Rousset 2008) and number of alleles and expected and observed heterozygosities using Gimlet. Poutanen et al. (2019) demonstrated that fecal sampling risks mistaking target and non-target species (roe deer, Capreolus capreolus ), but demonstrated that the only roe deer samples were those where seven or less microsatellites amplified. We therefore assumed that the 12 to 14 microsatellite markers used here were sufficient to exclude roe deer DNA and did not perform any additional species identification testing.

\section{Spatial Capture-Recapture}

We used Spatial Capture-Recapture with the R package oSCR (Sutherland et al. 2016) in RStudio (RStudio Team 2018) to examine white-tailed deer habitat selection i.e. how habitat affects white-tailed deer densities (D) and capture probabilities $\left(\mathrm{p}_{0}\right)$. We first chose the top homogeneous model without habitat covariates by AIC and continued fitting habitat covariates into the parameters of that model. This simplified the model selection procedure by reducing possible combinations of covariates (Efford and Fewster 2013, Brazeal et al. 2017). We constructed 42 different homogeneous models where we let $\mathrm{D}, \mathrm{p}_{0}$ and $\sigma$ (the spatial scale parameter) vary by year, sampling occasion, and sex. Supplementary Table S3 shows the combinations of fitted inhomogeneous models where $\mathrm{D}$ and $\mathrm{p}_{0}$ vary by different habitat covariates. All inhomogeneous models are modifications of the most supported homogeneous model. We also compared the overall predicted density estimates of the top homogeneous model with the top inhomogeneous SCR model including habitat covariates. We used multi-session SCR models with sampling year as a "session". The state space was defined by a grid with resolution $120 \mathrm{~m}$, which is about $0.5 \times \sigma$ based on the estimate of $\sigma$ from this study 
(see Results). A state space buffer of $1000 \mathrm{~m}$ around the traps was used.

Habitat covariates were defined using the open-source Corine Land Cover data (2012) provided by Finnish Environment Institute. For water bodies, we used the vector data of waterways provided by National Land Survey of Finland (2018). We considered three different habitat covariates for density. First was a categorical habitat class variable with four different levels: agricultural areas (fields), coniferous forests, mixed forests and transitional woodland/shrub. Other density covariates were distance to artificial areas (e.g. buildings, roads and other artificially surfaced areas) and distance to water. These covariates were assigned to the state space by extracting them from the Corine Land Cover raster data with a function extr.rast() (oSCR package) using the habitat which was the most frequent when summarizing the Corine Land Cover raster values (resolution $20 \mathrm{~m} \times 20 \mathrm{~m}$ ) around the central coordinates of the state space pixel on the same resolution as the state space is defined (here $120 \mathrm{~m}$ ). Artificial areas would have covered only $2 \%$ of the state space and those pixels were assigned to the habitat that was the second most frequent. Artificial areas and water bodies were included in the analysis by calculating the nearest distance from the state space pixel central coordinates to artificial area or water.

We included four different trap-level covariates to study how landcover type affects capture probability $\left(\mathrm{p}_{0}\right)$. The first covariate was a categorical landcover class variable with three different levels: coniferous forest, mixed forests, transitional woodland/shrub (hereafter: transitional woodland). Other three covariates for capture probability were distance to agricultural areas, distance to artificial areas, and distance to water bodies. To define the landcover class for each plot, the central coordinates of the sampling plots ("traps") were buffered by $30 \mathrm{~m}$ buffer and the proportion of each landcover type was calculated for the buffered area. The landcover type with the largest proportion in the buffered area was assigned as the landcover class for that plot. If two or more landcover types existed in exactly same proportions, then the class was defined using field notes on the landcover type of the central coordinate of the sampling plot. Only $3 \%$ of the 92 plots would have been assigned to deciduous forests. Because of this small proportion, this landcover class as trap-level covariate was changed to the class that covered the second largest proportion of the buffer area. To include agricultural areas, artificial areas and water bodies as covariates on capture probability, we calculated the nearest distance between the central coordinate of the plots and these landscape features.

\section{Results}

\section{Sampling and genetic analysis}

We collected 300 non-invasive white-tailed deer fecal samples in 2016 and 401 samples in 2017 during two (2016) and five (2017) sampling occasions (Table 1). Samples were found on 72\% (2016) and 79\% (2017) of the 92 sampling plots.

In total, $32 \%$ of the samples were successfully genotyped to the level permitting individual assignment (11 to 14 loci) in both years. Genetic summary statistics with per locus and mean values are presented in Supplementary Table S1. We identified 38 different white-tailed deer individuals (26 females and 12 males) in 2016 and 66 individuals (41 females and 25 males) in 2017. In total 17 (14 females and 3 males) of the individuals captured in 2017 were also present in the 2016 data set. In 2016, samples of identified individuals were found on $43 \%$ of the plots and in 2017 in $51 \%$ of the plots. In 2016 , we recaptured $50 \%$ of the individuals one to four times and in 2017, 44\% of the individuals one to six times (Table 1). In 2016, only $17 \%$ of the genotyped males were recaptured, whereas $65 \%$ of the genotyped females were recaptured (Table 1). In 2017, $40 \%$ of the genotyped males and $46 \%$ of the females were recaptured.

\section{Landscape of the study area}

The state space of the study area was defined by buffering the minimum area rectangle of the sample units by 1000 meters, producing a state-space of $10.4 \mathrm{~km}^{2}$. Agricultural areas comprised $76 \%$ (548 of 725 pixels), coniferous forests $12 \%$ (88 pixels), mixed forests $6 \%$ (45 pixels) and transitional woodland $6 \%$ (44 pixels) (Figure 1). $51.1 \%$ of the plots (47 of 92 plots) were coniferous forest, $30.4 \%$ (28 plots) mixed forest and $18.5 \%$ (17 plots) transitional woodland. 


\section{Spatial Capture-Recapture analysis}

We first considered all candidate models ignoring habitat heterogeneity. Among the 42 homogeneous models evaluated (Supplementary Table S2), the top model supported session i.e. density varied by year and baseline detection probability varied with sampling occasion, sex and year. The movement parameter $\sigma$ varied with the interaction of sex and year.

We included habitat covariates for density and detection probability in the top model and evaluated 24 different inhomogeneous candidate models (Supplementary Table S3). The homogeneous null model ranked as the ninth model with an approximately 25 AIC difference relative to the top model that included habitat characteristics (Table 2). According to the most supported inhomogeneous model, white-tailed deer density was dependent on landcover-type (agricultural areas, coniferous forests, mixed forests and transitional woodland) and detection probability varied with landcover-type (coniferous forest, mixed forests, transitional woodland) as well as distance to agricultural areas (Table 2, Table 3). Distance to water bodies or distance to artificial areas were not supported for either density or detection probability (Supplementary Table S3).

White-tailed deer densities were highest in agricultural areas and mixed forest and lowest in coniferous forests and transitional woodlands during both years (Figure 2, Table 3). Density was session-dependent and was higher during the second year compared to the first year (Figure 2, Table 3).

Detection probability i.e. the probability of capturing an individual at its home range center was highest in transitional woodlands, second highest in mixed forests and lowest in coniferous forests (Table 4). Detection probability decreased with distance to agricultural areas. During the first year, detection probability was higher than during the second year, which was expected, as the sampling interval was shorter in the second year. Overall, females had a slightly higher probability of being detected than males, with $\mathrm{p}_{0}=0.10$ for females and $\mathrm{p}_{0}=0.08$ for males. The average detection probability was 0.09 and varied between 0.02 and 0.24 (Table 4).

The spatial scale parameter $\sigma$ varied with the interaction of sex and year. For females, $\sigma$ was larger in the first sampling year compared to the second. Male $\sigma$ did not differ between years. Female $\sigma$ was higher than that of males in the first year but in the second year $\sigma$ was similar between the sexes. However, the confidence intervals generally overlap (Figure 3). Because space use by males was smaller than that of females, the estimated sex ratio $(\psi)$ based on SCR under the top model was about equal (0.52) despite the fact that more female than male individuals were identified (Table 1).

Density estimates were higher for the heterogeneous landscape compared with assuming a homogeneous landscape. The homogeneous top model predicted that the overall density of white-tailed deer across the whole state space was 111.7 (109.5-113.8) deer/1000 ha in 2016 and 254.9 (249.8-259.9) deer/1000 ha in 2017. The inhomogeneous top model with habitat covariates predicted that the overall density was 131.0 (126.1-135.9) deer/ 1000 ha in 2016 and 317.0 (304.9-329.0) deer/ 1000 ha in 2017.

\section{Discussion}

Knowledge of habitat selection is essential for evaluation of wildlife population density in a heterogeneous landscape. We find that inclusion of habitat heterogeneity is favored in the Spatial Capture-Recapture (SCR) model parameters of density and detection. The SCR model without landscape effects was 25 AIC units higher than the top model including landscape heterogeneity. The estimated densities across the habitats describe second-order habitat selection of the white-tailed deer population studied. Population densities were highest in agricultural areas and mixed forests and lowest in coniferous forests and transitional woodlands. We can integrate this preference over all landcover types in the study area to arrive at a landscape-specific estimate of density. We find that including heterogeneity increases the overall density estimate when compared with density estimated under the best supported homogeneous (constant density) SCR model. The increase in density is because the greatest proportion of the state space consists of agricultural areas (76\%), which is also the preferred habitat (together with mixed forests which are, however, relatively uncommon).

In the SCR framework, we estimated habitat-specific densities, while accounting for third- order habitat 
selection through the effect of habitat on detection probability. The probability to detect an individual is highest in transitional woodland followed by mixed forest and is lowest in coniferous forest. Detection probability also decreases with increasing distance to land in agricultural use. Thus, inside a white-tailed deer's home range, space is not used equally; the animals prefer to be close to fields and in transitional woodland compared to coniferous forest. In our study area, transitional woodlands are typically clear-cuts and these, as well as fields which are predominantly grain fields (wheat, oat, rye), likely present habitat with good food resources for the white-tailed deer.

About half (52\%) of the white-tailed deer in the study area are males. This is an interesting finding, because the age and sex composition of the white-tailed deer is almost entirely shaped by the strong hunting pressure on this species. In general, harvested ungulate populations tend to have more females than males in Nordic countries, which may result in lower viability of the population (Langvatn and Loison 1999, Sæther et al. 2004). Hunting-bag statistics of white-tailed deer in Finland also imply a higher mortality of males and as a result, few males compared to females reach old ages (Kekkonen et al. 2016). However, DNA does not allow distinguishing fawns from adults, and fawns are probably a large fraction of the study population. Because home ranges of fawns are restricted to their mothers' (Tierson et al. 1985), and because the spatial scale of the study is small and the number of individuals limited, our results may largely reflect fawns and their mothers. Based on the 17 individuals recorded in both study years, we can infer that at least $34 \%(14 / 41)$ of females and $12 \%(3 / 25)$ of males were adults in the second study year. For these reasons, the sex ratio of Finnish white-tailed deer would need more thorough investigation.

Our study area represents a typical Finnish rural area with low coverage of artificial surfaces (covering only $2 \%$ of the state space). Here, we did not find any preference or avoidance by white-tailed deer for artificial surfaces, which includes roads and human settlements. We expected that the distance to water, which in the study area were mainly two bigger streams with smaller ditches, would have been an important covariate for white-tailed deer density. Nevertheless, the models including that covariate were not supported by AIC. Presumably, there are other smaller stationary water sources in the area and thus larger streams and ditches are not the crucial source of water for white-tailed deer. It is notable that the habitat preferences later in the year likely differ, especially during winter when food sources are different and limited. In addition, snow cover may affect the availability of food and movement of individuals (Andersson and Koivisto 1980).

Collecting information on space use of individuals based on non-invasive genetic methods and analyzing this information with SCR provides a possibility to study habitat selection of animal populations, as done in this study. A possible advantage of this approach compared to telemetry approaches is that population-wide inferences can be reached at a potential lower cost and with clearly lower risk to the study organism. In addition, multilocus genotype data provides information not only for individual identification and density estimation, but also to study the genetic diversity and structure of populations, or relatedness and pedigree of individuals (Granroth-Wilding et al. 2017, Sun et al. 2017, Hagemann et al. 2018). However, DNA data alone does not provide information on age structure of the population, but integrating it with camera trapping data could provide this information (Furnas et al. 2018). Furthermore, non-invasive methods combined with telemetry of a few individuals can improve precision of SCR estimates by incorporating additional movement information (Royle et al. 2013a, Sollmann et al. 2016, Linden et al. 2018). Although the approach may vary, our findings add to the growing SCR-based evidence that it is important to consider the spatial heterogeneity of an area and habitat selection of animals. By acknowledging that landscapes are heterogeneous and incorporating that into our analyses, we quantify habitat selection, which captures crucial ecology in terms of how the organism uses its environment both in terms of population density and in terms of individual space use.

\section{Acknowledgements}

We would like to thank the local hunting club who helped us with deciding the study area and contacting the landowners. Moreover, we thank the landowners for permission to work on their property. Many thanks for the three field assistants who helped us with collecting the samples and one of them working also as a lab assistant with DNA analysis. This work was funded by the Ministry of Agriculture and Forestry. The project 
was funded by the Ministry of the Agriculture and Forestry. JPo was funded by the Doctoral Programme in Biology, Geography and Geology and received grants also from Jenny and Antti Wihuri foundation, Societas Pro Fauna et Flora Fennica and Suomen Riistanhoito-Säätiö. Any use of trade, firm, or product names is for descriptive purposes only and does not imply endorsement by the U.S. Government.

\section{Conflict of interest}

The authors declare they have no conflicting interests.

\section{Author contributions}

Jenni Poutanen: Conceptualization (equal); Data Curation (lead); Formal analysis (lead); Funding acquisition (equal); Investigation (lead); Writing-original draft (lead); Writing-review \& editing (equal). Angela K. Fuller: Formal analysis (equal); Writing-review \& editing (equal). Jyrki Pusenius: Funding acquisition (equal); Project administration (equal); Writing-review \& editing (equal). J. Andrew Royle: Formal analysis (equal); Writing-review \& editing (equal). Mikael Wikström: Funding acquisition (equal); Project administration (equal); Writing-review \& editing (equal). Jon E. Brommer: Conceptualization (equal); Data Curation (equal); Formal analysis (equal); Funding acquisition (equal); Project administration (lead); Supervision (lead); Writing-original draft (equal); Writing-review \& editing (equal).

\section{Data availability statement}

The fecal DNA data (coordinates of the sampling plots, microsatellite genotypes of the individuals and individual encounter histories) for spatial capture-recapture modeling and the $\mathrm{R}$ script for conducting these models will be available from the repository Dryad upon acceptance.

\section{References}

Allen, A. M., \& Singh, N. J. (2016). Linking Movement Ecology with Wildlife Management and Conservation. Frontiers in Ecology and Evolution, 3.

Andersson, E., \& Koivisto, I. (1980). Valkohäntäpeuran talviravinto ja vuorokausrytmi (White-tailed deer's winter food and diurnal rhythm).Suomen Riista , 27, 84-92.

Bjørneraas, K., Herfindal, I., Solberg, E. J., Sæther, B-E., van Moorter, B., \& Rolandsen, C. M. (2012). Habitat quality influences population distribution, individual space use and functional responses in habitat selection by a large herbivore. Oecologia , 168(1), 231-243.

Bose, S., Forrester, T. D., Casady, D. S., \& Wittmer, H. U. (2018). Effect of activity states on habitat selection by black-tailed deer. The Journal of Wildlife Management, 82(8), 1711-1724.

Brazeal, J. L., Weist, T., \& Sacks, B. N. (2017). Noninvasive genetic spatial capture-recapture for estimating deer population abundance. The Journal of Wildlife Management , 81(4), 629-640.

Efford, M. (2004). Density estimation in live-trapping studies.Oikos , 106(3), 598-610.

Efford, M. G., \& Fewster, R. M. (2013). Estimating population size by spatially explicit capture-recapture. Oikos , 122(6), 918-928.

Finnish Ministry of Agriculture and Forestry. (2012). Finland's National Strategy on Invasive Alien Species.

Fretwell, S. D. (1969). On territorial behavior and other factors influencing habitat distribution in birds. Acta Biotheoretica , 19(1), 45-52.

Fuller, A., Sutherland, C. S., Royle, A. R., \& Hare, M. P. (2016). Estimating population density and connectivity of American mink using spatial capture - recapture. Ecological Applications , 26(4), 1125-1135.

Furnas, B. J., Landers, R. H., Hill, S., Itoga, S. S., \& Sacks, B. N. (2018). Integrated modeling to estimate population size and composition of mule deer. The Journal of Wildlife Management, 82(7), 1429-1441. 
Granroth-Wilding, H., Primmer, C., Lindqvist, M., Poutanen, J., Thalmann, O., Aspi, J., Harmoinen, J., Kojola, I., \& Laaksonen, T. (2017). Non-invasive genetic monitoring involving citizen science enables reconstruction of current pack dynamics in a re-establishing wolf population. BMC ecology , 17(1), 44.

Hagemann, L., Boesch, C., Robbins, M. M., Arandjelovic, M., Deschner, M. L., Froese, G., \& Vigilant, L. (2018). Long-term group membership and dynamics in a wild western lowland gorilla population (Gorilla gorilla gorilla) inferred using non-invasive genetics. American Journal of Primatology, 80(8), e22898.

Halls, L. K. (1984). White-tailed deer: Ecology and Management.Stackpole Books .

Honzová, M. (2013) Analysis of habitat size and migration of roe and white-tailed deer in Finnish lake district, Finland. Diploma Thesis. Mendel University in Brno.

Jansson, E., Harmoinen, J., Ruokonen, M., \& Aspi, J. (2014). Living on the edge: reconstructing the genetic history of the Finnish wolf population. BMC Evolutionary Biology , 14, 64.

Johnson, D. H. (1980). The Comparison of Usage and Availability Measurements for Evaluating Resource Preference. Ecology , 61(1), 65-71.

Kekkonen, J., Wikström, M., Ala-Ajos, I., Lappalainen, V., \& Brommer, J. E. (2016). Growth and Age Structure in an Introduced and Hunted Cervid Population: White-Tailed Deer in Finland. Annales Zoologici Fennici, 53(1-2), 69-80.

Langvatn, R. and Loison, A. (1999). Consequences of harvesting on age structure, sex ratio and population dynamics of red deer Cervus elaphus in central Norway. Wildlife Biology , 5(4), 213-223.

Linden, D. W., Sirén, A. P. K, \& Pekins, P. J. (2018). Integrating telemetry data into spatial capturerecapture modifies inferences on multi-scale resource selection. Ecosphere , 9(4), e02203.

Maier, J. A. K., Ver Hoef, J. M., McGuire, A. D, Bowyer, R. T., Saperstein, L., \& Maier, H. A. (2005). Distribution and density of moose in relation to landscape characteristics: effects of scale.Canadian Journal of Forest Research , 35(9), 2233-2243.

Morris, L. R., Proffitt, K. M., Asher, V., \& Blackburn, J. K. (2016). Elk resource selection and implications for anthrax management in Montana. The Journal of Wildlife Management , 80(2), 235-244.

National Land Survey of Finland. 2018: Open data CC 4.0 licence. Waterway data from Topographic map series in vector format 1:100 000, accessed 1 October 2018.

O'Meara, D. B., McDevitt, A. D., O'Neill, D., Harrington, A. P., Turner, P., Carr, W., Desmond, M., Lawton, C., Marnell, F., Rubalcava, S., Sheehy, E., Sleeman, D. P., Tosh, D., Waters, C., \& O'Reilly, C. (2018). Retracing the history and planning the future of the red squirrel (Sciurus vulgaris) in Ireland using non-invasive genetics.Mammal Research , 63.

Poutanen, J., Pusenius, J., Wikström, M., \& Brommer, J. E. (2019). Estimating Population Density of the White-Tailed Deer in Finland using Non-Invasive Genetic Sampling and Spatial Capture-Recapture.Annales Zoologici Fennici , 56(1-6), 1-16.

Proffitt, K. M., Goldberg, J. F., Hebblewhite, M., Russell, R., Jimenez, B. S., Robinson, H. S., Pilgrim, K., \& Schwartz, M. K. (2015). Integrating resource selection into spatial capture-recapture models for large carnivores. Ecosphere, 6(11), art239.

Royle, J. A., Chandler, R. B., Sun, C. C., \& Fuller, A. K. (2013a). Integrating resource selection information with spatial capture-recapture. Methods in Ecology and Evolution , 4(6), 520-530.

Royle, J. A., Chandler, R. B., Gazenski, K. D., \& Graves, T. A. (2013b). Spatial capture-recapture models for jointly estimating population density and landscape connectivity. Ecology , 94(2), 287-294.

Royle, J. A., Richard, B., Chandler, R. B., Sollmann, R., \& Gardner, B. (2014). Spatial capture-recapture. Elsevier . 
Royle, J. A., Fuller, A. K., \& Sutherland, C. (2018). Unifying population and landscape ecology with spatial capture-recapture.Ecography , 41(3), 444-456.

RStudio Team. 2018: RStudio: Integrated Development for R. RStudio, Inc., Boston, MA URL http://www.rstudio.com/.

Sæther, B-E., Solberg, E.J, Heim, M, Stacy, J.E., Jakobsen, K.S., \& Olstad, R. (2004). Offspring sex ratio in moose Alces alces in relation to paternal age: An experiment. Wildlife Biology , 10(1), 51-57.

Sollmann, R., Gardner, B., Belant, J. L, Wilton, C. M., \& Beringer, J. (2016). Habitat associations in a recolonizing, low-density black bear population. Ecosphere, 7(8), e01406.

Stansbury, C. R., Ausband, D. E., Zager, P., Mack, C. M., Miller, C. R., Pennell, M. W., \& Waits, L. P. (2014). A long-term population monitoring approach for a wide-ranging carnivore: Noninvasive genetic sampling of gray wolf rendezvous sites in Idaho, USA. The Journal of Wildlife Management , 78, 1040-1049.

Stetz, J. B., Mitchell, M. S., \& Kendall, K. C. (2019). Using spatially-explicit capture-recapture models to explain variation in seasonal density patterns of sympatric ursids. Ecography , 42(2), 237-248.

Sun, C. C., Fuller, A. K., Hare, M. P., \& Hurst, J. E. (2017). Evaluating population expansion of black bears using spatial capture-recapture. The Journal of Wildlife Management , 81(5), 814-823.

Sutherland, C., Royle, J. A., \& Linden, D. (2016). oSCR: Multi-Session Sex-Structured Spatial 503 CaptureRecapture Models. R package version 0.30.0. https://github.com/jaroyle/oSCR.

Sutherland, C., Fuller, A. K., \& Royle, J. A. (2015). Modelling non-Euclidean movement and landscape connectivity in highly structured ecological networks. Methods in Ecology and Evolution , 6(2), 169-177.

Taberlet, P., Griffin, S., Goossens, B., Questiau, S., Manceau, V., Escaravage, N., Waits, L. P., \& Bouvet, J. (1996). Reliable genotyping of samples with very low DNA quantities using PCR. Nucleic Acids Research , 24(16), 3189-3194.

Tierson, W. C., Mattfeld, G. F., Sage, R. W., \& Behrend, D. F. (1985). Seasonal Movements and Home Ranges of White-Tailed Deer in the Adirondacks. The Journal of Wildlife Management , 49(3), 760-769.

Waits, L. P., Luikart, G., \& Taberlet, P. (2001). Estimating the probability of identity among genotypes in natural populations: cautions and guidelines. Molecular Ecology , 10(1), 249-256.

Waits, L. P., \& Paetkau, D. (2005). Noninvasive Genetic Sampling Tools for Wildlife Biologists: A Review of Applications and Recommendations for Accurate Data Collection. The Journal of Wildlife Management , 69(4), 1419-1433.

Welfelt, L. S., Beausoleil, R. A., \& Wielgus, R. B. (2019). Factors Associated with black bear density and implications for management. The Journal of Wildlife Management, 83(7), 1527-1539.

\section{Figure captions}

Figure 1. Landscape of the study area in Loimaa, Southwest Finland. Larger black dots indicate DNA sampling plots for white-tailed deer and smaller black dots form the state space with $120 \mathrm{~m}$ resolution.

Figure 2. Predicted densities of white-tailed deer per 1000ha in different landcover types in study area in southwestern Finland during 2016 and 2017.

Figure 3. Spatial scale parameter $\sigma$ for white-tailed deer in Finland, varying with the interaction of sampling year and sex. $\sigma$ describes the movement radius of individuals during the study. Estimates are presented in meters with $95 \%$ confidence intervals.

\section{Tables}

Table 1. Summary of the white-tailed deer non-invasive fecal samples collected in 92 sampling plots in two years in the study area in Southwest Finland. 


\begin{tabular}{lll}
\hline Year & 2016 & 2017 \\
\hline No of collected samples & 300 & 401 \\
Successfully genotyped ([?] 11 loci) & $94(31 \%)$ & $130(32 \%)$ \\
No of individuals $(/)$ & $38(12 / 26)$ & $66(25 / 41)$ \\
Sex ratio $(/)$ & 0.46 & 0.61 \\
Individual detections (/) & $76(16 / 60)$ & $121(40 / 81)$ \\
No of recaptured individuals $(/)$ & $19(2 / 17)$ & $29(10 / 19)$ \\
recaptured once $(/)$ & $5(0 / 5)$ & $11(5 / 6)$ \\
recaptured twice $(/)$ & $11(2 / 9)$ & $13(5 / 8)$ \\
recaptured three times $(/)$ & $1(0 / 1)$ & $4(0 / 4)$ \\
recaptured four times $(/)$ & $2(0 / 2)$ & - \\
recaptured six times $(/)$ & - & $1(0 / 1)$ \\
Recapture rate & $50 \%$ & $44 \%$ \\
\hline
\end{tabular}

Table 2. Eight candidate Spatial Capture-Recapture models (1-8) for estimating density of white-tailed deer by assuming an inhomogeneous landscape. Models include habitat covariates for density (D) and detection probability (p). These eight models received the best support compared to the top model assuming a homogeneous landscape (model 9, in bold). Full set of models are reported in Table S2 and S3.

\begin{tabular}{lllll}
\hline Model & $\operatorname{logL}$ & $\mathrm{K}$ & AIC \\
\hline 1 & D(session + habitatclass) p (t + sex + session + DistanceAgr + habitatclass) sig(session*sex) & 799.3700 & 20 & 1638. \\
2 & D(session + habitatclass) p(t + sex + session + DistanceAgr) sig(session*sex) & 803.2589 & 18 & 1642. \\
3 & D(session + habitatclass) p(t + sex + session + habitatclass) sig(session*sex) & 803.8769 & 19 & 1645. \\
4 & D(session) p(t + sex + session + DistanceAgr) sig(session*sex) & 808.6710 & 15 & 1647. \\
5 & D(session + habitatclass) p (t + sex + session) sig(session*sex) & 808.0432 & 17 & 1650. \\
6 & D(session + habitatclass) p(t + sex + session + DistanceWater) sig(session*sex) & 808.0297 & 18 & 1652. \\
7 & D(session + habitatclass) p(t + sex + session + DistanceArtificial) sig(session*sex) & 808.7526 & 18 & 1653. \\
8 & D(session) p(t + sex + session + habitatclass) sig(session*sex) & 814.3411 & 16 & 1660. \\
$\mathbf{9}$ & D(session) p(t + sex + session) sig(session*sex) & $\mathbf{8 1 7 . 8 7 0 5}$ & $\mathbf{1 4}$ & $\mathbf{1 6 6 3}$ \\
\hline
\end{tabular}

Table 3. Variables affecting parameters in the most parsimonious Spatial Capture-Recapture model when estimating white-tailed deer population density by assuming heterogeneous landscape ( (session + habitatclass $) \mathrm{p}(\mathrm{t}+\mathrm{sex}+$ session + DistanceAgr + habitatclass $) \operatorname{sig}\left(\right.$ session* $\left.{ }^{*} \mathrm{sex}\right)$.

\begin{tabular}{|c|c|c|c|c|}
\hline Parameter & Covariate & Definition & Variables & \\
\hline \multirow[t]{2}{*}{ density (D) } & session & sampling year & 2016,2017 & 2016,2017 \\
\hline & habitatclass & $\begin{array}{l}\text { habitat on state } \\
\text { space }\end{array}$ & $\begin{array}{l}\text { conicultural areas, } \\
\text { mixed forest, } \\
\text { transitional } \\
\text { woodland } \\
\text { male, female }\end{array}$ & $\begin{array}{l}\text { agricultural areas, } \\
\text { coniferous forest, } \\
\text { mixed forest, } \\
\text { transitional } \\
\text { woodland } \\
\text { male, female }\end{array}$ \\
\hline \multirow{3}{*}{$\begin{array}{l}\text { detection } \\
\text { probability }\left(\mathrm{p}_{0}\right)\end{array}$} & $\mathrm{t}$ & occasion & $\# 1-2$ in $2016, \# 1-5$ & $\# 1-2$ in $2016, \# 1-5$ \\
\hline & & - & $\begin{array}{l}\text { in } 2017 \\
\text { male, female }\end{array}$ & $\begin{array}{l}\text { in } 2017 \\
\text { male, female }\end{array}$ \\
\hline & DistanceAgr & $\begin{array}{l}\text { distance to } \\
\text { agricultural areas }\end{array}$ & - & - \\
\hline
\end{tabular}




\begin{tabular}{lllll}
\hline Parameter & Covariate & Definition & Variables & \\
\hline & habitatclass & habitat $30 \mathrm{~m}$ & coniferous forest, & coniferous forest, \\
& & around the & mixed forest, & mixed forest, \\
& sampling plots & transitional & transitional \\
& & & woodland & woodland \\
\multirow{2}{*}{$\operatorname{sigma}(\mathrm{sig}, \sigma)$} & session & - & 2016,2017 & 2016,2017 \\
& sex & & male, female & male, female \\
\hline
\end{tabular}

Table 4. Detection probabilities of white-tailed deer in different landcover classes during different sampling occasions in two study years 2016 and 2017 in Southwest Finland. Lowest and highest estimates are bolded. In addition to these parameters, detection declined with distance to agricultural areas (slope of logit of detection was -0.006 per meter).

\begin{tabular}{|c|c|c|c|c|}
\hline Year & Occasion & Landcover class & $\mathrm{p}_{0}$ female & $\mathrm{p}_{0}$ male \\
\hline \multirow{6}{*}{2016} & \multirow[t]{3}{*}{1} & Coniferous & 0.11 & 0.09 \\
\hline & & Mixed & 0.15 & 0.12 \\
\hline & & Transitional woodland & 0.18 & 0.14 \\
\hline & \multirow[t]{3}{*}{2} & Coniferous & 0.15 & 0.12 \\
\hline & & Mixed & 0.21 & 0.16 \\
\hline & & Transitional woodland & 0.24 & 0.19 \\
\hline \multirow[t]{15}{*}{2017} & \multirow[t]{3}{*}{1} & Coniferous & 0.04 & 0.03 \\
\hline & & Mixed & 0.06 & 0.04 \\
\hline & & Transitional woodland & 0.07 & 0.05 \\
\hline & \multirow[t]{3}{*}{2} & Coniferous & 0.05 & 0.04 \\
\hline & & Mixed & 0.08 & 0.06 \\
\hline & & Transitional woodland & 0.09 & 0.07 \\
\hline & \multirow[t]{3}{*}{3} & Coniferous & 0.03 & 0.02 \\
\hline & & Mixed & 0.04 & 0.03 \\
\hline & & Transitional woodland & 0.05 & 0.04 \\
\hline & \multirow[t]{3}{*}{4} & Coniferous & 0.09 & 0.07 \\
\hline & & Mixed & 0.12 & 0.09 \\
\hline & & Transitional woodland & 0.14 & 0.11 \\
\hline & \multirow[t]{3}{*}{5} & Coniferous & 0.07 & 0.06 \\
\hline & & Mixed & 0.10 & 0.08 \\
\hline & & Transitional woodland & 0.12 & 0.10 \\
\hline
\end{tabular}



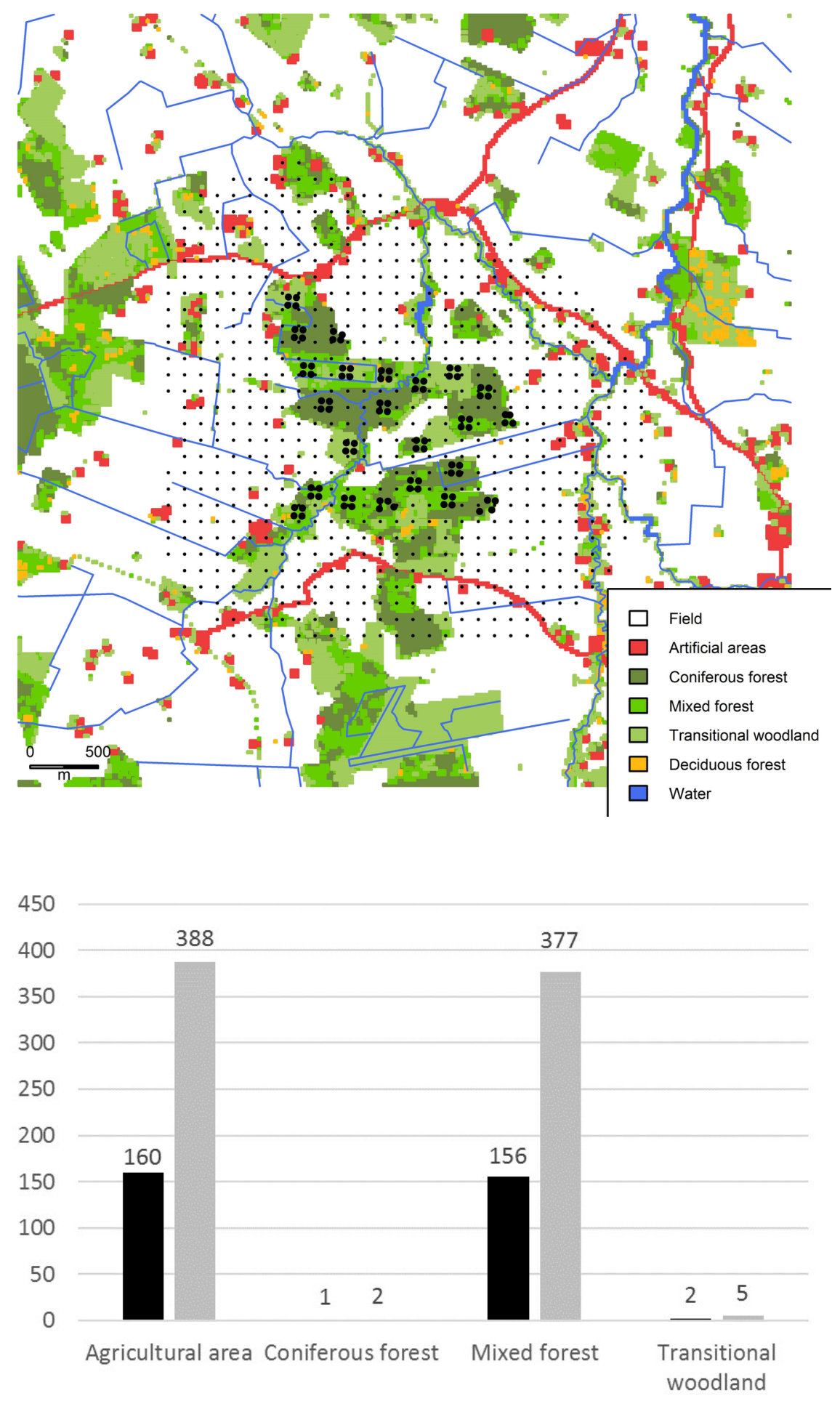

ロ 2016 - 2017 


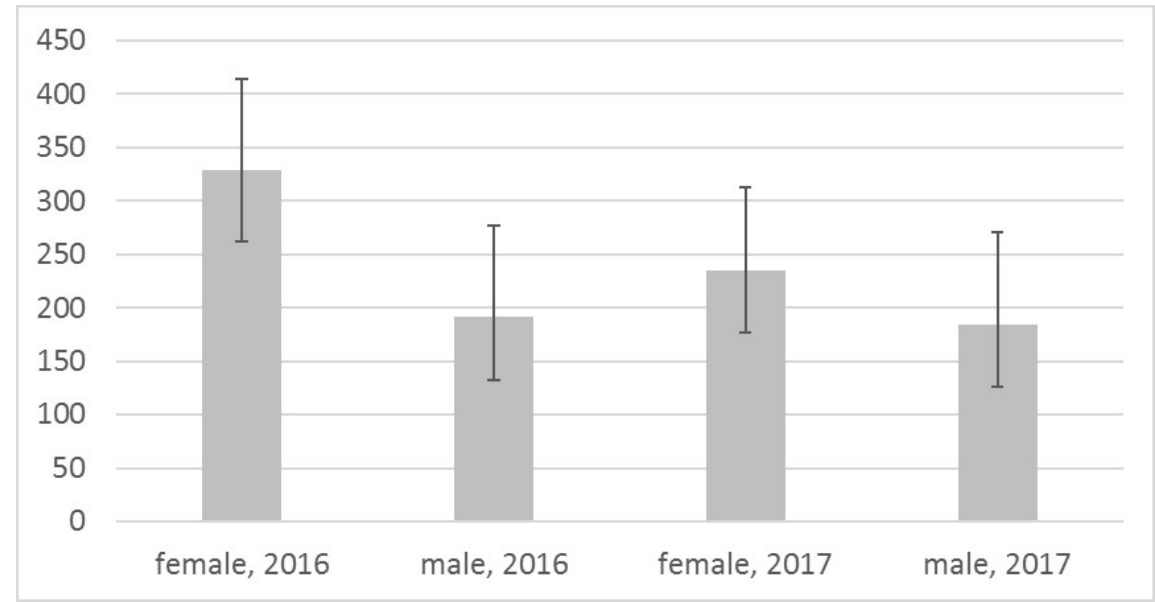

